\title{
Determination of Moisture Index in Korea ${ }^{1}$
}

\author{
Jong Bum $\mathrm{Ra} \mathbb{D}^{2, \dagger}$
}

\begin{abstract}
This study aimed to obtain basic climate information for effective moisture control in wood in Korea. Two independent climate indexes, namely drying index (DI) and wetting index (WI), were determined using hourly weather data for 82 locations recorded from 2009 to 2017. These data were collected from the Korea Meteorological Administration (KMA). Hourly data had not been measured prior to 2009. DI and WI revealed that all regions were cold and wet except Baengnyeongdo, which was classified as a cold and dry region. DI and WI were normalized assuming that wetting and drying were equally important phenomena. Then, the normalized indexes were combined into moisture index (MI) to rank the moisture loading of the regions. The MIs showed that Seogwipo had the greatest moisture loading in Korea, followed by Seongsan, Namhae, and Geoje. The MIs suggested that Korea exhibited severe moisture loading. Further studies are required to investigate the relation between MI and moisture content on wood surfaces from a wood maintenance point of view.
\end{abstract}

Keywords: drying index, wetting index, moisture index

\section{INTRODUCTION}

One of the fundamental principles in wood science is that wood or wooden materials must be suited to their exposed climate to prevent premature failures. Such problems have been particularly reported in various regions of North America (Chouinard and Lawton, 2001; Cornic et al., 2002; Cornick and Dalgliesh, 2003). Thus, determining the moisture loading level in a given location is important for the prevention of deterioration and the maintenance of exposed surfaces of wooden constructions.

Currently, several climate indexes based on temperature-rainfall combinations have been developed to help designers and builders (Lstiburek, 2001; Russo, 1971). They were determined based on either wind-driven rain or the decay risk of wood used for exterior aboveground applications (Boyd, 1963; Kim et al., 2011; Kim and Ra, 2013, 2014; Ra, 2017; Setliff, 1986). Although these climate classifications were useful, they were not developed to evaluate potential moisture loading on the envelopes of materials, such as wood. The requirement for a more quantitative index than the available indexes resulted in the development of a moisture index (MI) (Cornick et al., 2002; Cornick and Dalgliesh, 2003).

MI is a function of wetting index (WI) and drying index (DI) that express the moisture entry and exit,

${ }^{1}$ Date Received February 27, 2018, Date Accepted June 19, 2018

2 Department of Interior Materials Engineering, Gyeongnam National University for Science and Technology, 33 Dongjin-Ro, Jinju 52725, Republic of Korea

† Corresponding author: Jong-Bum Ra (e-mail: jb@gntech.ac.kr, ORCID: 0000-0002-5015-7319) 
respectively (Bailey, 1958; Cornick et al., 2002; Cornick and Dalgliesh, 2003). Since WI is defined as the wettability of wood, it can be effectively measured by determining the availability of water using rainfall and driving-rain indexes (Cornick et al., 2002). DI is defined as the potential evaporation for a given location. The potential evaporation is defined as the possible room in a parcel of air that is available for moisture take up. Cornick et al., (2002) combined WI and DI to determine the MI of cities in Canada and the United States.

The potential for moisture loading in various climates can be determined by calculating the MI using the available climate data. Because the method of calculating the MI is general, it can also be used to compare the amount of moisture loading in different regions. This study aims to determine the MIs in various regions of Korea to obtain basic climate information for effective moisture control.

\section{MATERIALS and METHODS}

Domestic hourly weather data recorded from 2009 to 2017 were obtained from the Korea Meteorological Administration (KMA) for 82 stations, including Seoul. Most weather data were measured every third hour prior to 2009. The hourly data of interest were temperature, precipitation, relative humidity, vapor pressure, and spot atmospheric pressure. Spot atmospheric pressure is the atmospheric pressure at the measured site, not the pressure modified to the sea level.

Herein, rainfall was used as WI. Rainfall was the preferred parameter over driving-rain indexes because it is strongly correlated and commonly available for most locations (Cornick et al., 2002). And DI was calculated using equations (1), (2), and (3). It is more convenient to use long-term climate data instead of hourly data because of low amount of data. However, the use of long-term data has been reported to underestimate the DI by 21\% (Cornick et al., 2002).

$$
\begin{gathered}
\Delta w(h)=w_{\text {saturation }}\left(\text { hourly }_{\text {temperature }}\right) \\
-w_{\text {out }}\left(\text { hourly }_{\text {temperature }}\right) \\
w=0.622 \times\left(v_{p} /\left(p-v_{p}\right)\right) \text { kgwater } / \text { kgair } \\
D I=\frac{1}{n} \sum_{i=1}^{n} \sum_{h=1}^{k} \Delta w(h)
\end{gathered}
$$

where $w$ is the humidity ratio ( $\mathrm{kg}$ water $/ \mathrm{kg}$ air), $v_{p}$ is the vapour pressure $(\mathrm{kPa}), p$ is the total mixture pressure $(\mathrm{kPa}), D I$ is the Drying Index ( $\mathrm{kg}$ water $/ \mathrm{kg}$ air-year), $n$ is the number of years under consideration, and $k$ is the number of hours in a particular year.

DI and WI were calculated for each year for a particular location and were combined into a MI. A higher MI suggests a greater potential for moisture loading (Cornick and Dalgliesh, 2003).

Both WI and DI were normalized to have values from 0 to 1 and combined into a MI using equation (4).

$$
I_{\text {normalized }}=\left(I-I_{\min }\right) /\left(I_{\max }-I_{\min }\right) \cdots \cdots \cdots
$$

For comparison, WIs and DIs of 20 cities in Canada and the United States determined by Cornick et al., (2002) were included in the dataset. The obtained WIs were normalized to that in Seogwipo, Korea, and DIs were normalized to that in Phoenix, Arizona, which had indexes of 2091.94 and 129.47, respectively.

Wetting and drying were assumed as equally important phenomena and were therefore given equal weight in the determination of the MI using equation (5).

$$
M I=\sqrt{W I_{\text {normalized }}^{2}+\left(1-D I_{\text {normalized }}\right)^{2}}
$$


The determined MIs were compared and analyzed to evaluate the level of moisture loading.

\section{RESULTS and DISCUSSION}

Table 1 lists the average domestic weather data and the determined values of the DI, WI, and MI. Herein, WI was defined based on the total rainfall in a region and the DI was determined using the hourly weather data obtained from 82 locations from 2009 to 2017.

The average annual temperature varied from $7.39^{\circ} \mathrm{C}$ to $16.96^{\circ} \mathrm{C}$ depending on the location. Seogwipo showed the highest temperature, followed by Jeju, Gosan, and Seongsan. The location with the lowest temperature was Daegwallyeong. The average annual precipitation showed values between 739.17 and $2091.94 \mathrm{~mm}$. Seogwipo and Seongsan had an annual precipitation level of $>2,000 \mathrm{~mm}$, and Baengnyeongdo had the lowest annual precipitation of $739.17 \mathrm{~mm}$. The annual relative humidity (RH) was $~ 65 \%$. The highest annual average RH was $80 \%$ in Mokpo, and the lowest was 57.94\% in Gangneung. According to Russo's classification scheme (Russo, 1971), most domestic regions can be classified as mild and wet regions.

DI was calculated using the hourly climate data and ranged between 10.7 and 18.03. Seogwipo had the highest DI, followed by Gosan, Seongsan, and Mokpo. Daegwallyeong had the lowest DI. A high DI suggests that the potential drying capacity would be higher. Among the North American cities, Vancouver and Victoria, BC, Canada, have DIs similar to those in Korea. Their values are 16.10 and 17.03 , respectively (Cornick et al., 2002; Cornick and Dalgliesh, 2004).

Fig. 1 plots DI versus WI, where each point represents the nine-year average indexes calculated from the data for 82 locations. Cornick et al., (2002) divided the climate zones into four categories using DI and WI. A DI of $\sim 20$ and a WI of $\sim 800$ were used as references to distinguish between hot and cold regions as well as wet and dry regions, respectively. According to this scheme, all regions of Korea, except Baengnyeongdo, can be classified as cold and wet regions. Baengnyeongdo is the only cold and dry region. Cities occupying the lower right-hand corner of the plot have low DIs and high WIs and can be assumed to have a high potential for moisture loading. The plot also suggests that the potential moisture loading would increase with an increasing WI.

The variation in DI between the regions in Korea is not severe when compared with those in Canada and the United States. If the range of the DI is varied significantly, the ranking will be changed, making it impossible to compare the MI between regions. Therefore, the determined WIs and DIs of several cities in Canada and the United States were normalized. In this study, the WI was normalized to that in Seogwipo, Korea, whereas the DI was normalized to that in Phoenix, Arizona, because Seogwipo and Phoenix had the maximum WI of 2091.94 and the maximum DI of 129.47, respectively, in the given dataset.

In Korea, Baengnyeongdo had the lowest MI of 0.99. Other locations had MIs greater than those in Victoria, BC, Canada. Cornick and Dalgliesh (2003) used five divisions to categorize moisture loading. Their classifications ranged from zone 1 with low moisture loading to zone 5 with severe moisture loading. Victoria that has the MIs distinguishing between severe and high moisture loading zones according to Cornick et al., (2002), showed the MI of 1.02. Table 2 lists the calculated MIs of the cities in Canada and the United States. According to this criterion, Korea appears to be in zone 5, a division of severe moisture loading.

The high MI of Korea is due to its higher precipitation and RH. Although Korea lies in a severe moisture loading zone, it is not in a severe decay hazard zone. According to the Scheffer index, Korea is generally classified as a middle decay hazard region (Kim and $\mathrm{Ra}, 2013$, 2014). The reason for this is unclear but 
Jong Bum Ra

Table 1. Average annual moisture indexes calculated from hourly climate data for the period of 2009-2017.

\begin{tabular}{|c|c|c|c|c|c|c|c|c|}
\hline Location & $\begin{array}{c}\text { Temp } \\
\left({ }^{\circ} \mathrm{C}\right)\end{array}$ & $\begin{array}{l}\text { Average annual } \\
\text { Precipitation } \\
\text { (mm) }\end{array}$ & $\begin{array}{l}\text { RH } \\
\text { (\%) }\end{array}$ & $\begin{array}{c}\text { Vapor } \\
\text { pressure } \\
(\mathrm{hPa})\end{array}$ & $\begin{array}{c}\text { Spot } \\
\text { atmospheric } \\
\text { Pressure } \\
(\mathrm{hPa})\end{array}$ & DI & WI & MI \\
\hline Seoul & 12.81 & 1391.42 & 60.03 & 11.20 & 1005.89 & 12.84 & 1391.42 & $1.15 * 1$ \\
\hline Busan & 15.10 & 1519.02 & 62.16 & 12.99 & 1007.44 & 14.93 & 1519.02 & 1.17 \\
\hline Daegu & 14.59 & 1058.37 & 58.04 & 11.68 & 1009.26 & 13.40 & 1058.37 & 1.06 \\
\hline Daejeon & 13.18 & 1253.28 & 68.44 & 12.62 & 1008.31 & 14.52 & 1253.28 & 1.01 \\
\hline Gwangju & 14.32 & 1332.51 & 67.92 & 13.24 & 1007.97 & 15.24 & 1332.51 & 1.11 \\
\hline Ulsan & 14.39 & 1183.67 & 64.76 & 12.89 & 1010.48 & 14.82 & 1183.67 & 1.07 \\
\hline Incheon & 12.51 & 1202.26 & 71.74 & 13.08 & 1007.96 & 15.07 & 1202.26 & 1.08 \\
\hline Ganghwa & 11.32 & 1229.49 & 69.16 & 11.81 & 1010.83 & 13.56 & 1229.49 & 1.10 \\
\hline Baengnyeongdo & 11.22 & 739.17 & 70.74 & 11.64 & 998.93 & 13.34 & 739.17 & 0.99 \\
\hline Dongducheon & 11.62 & 1382.26 & 64.17 & 11.01 & 1002.80 & 12.61 & 1382.26 & 1.14 \\
\hline Suwon & 12.64 & 1345.37 & 69.58 & 12.63 & 1012.31 & 14.54 & 1345.37 & 1.12 \\
\hline Yangpyeong & 12.01 & 1400.94 & 67.91 & 11.72 & 1010.69 & 13.44 & 1400.94 & 1.14 \\
\hline Icheon & 11.66 & 1258.46 & 64.54 & 10.97 & 1007.07 & 12.54 & 1258.46 & 1.11 \\
\hline Paju & 11.01 & 1294.66 & 70.54 & 11.79 & 1012.84 & 13.59 & 1294.66 & 1.11 \\
\hline Sokcho & 12.64 & 1274.1 & 64.92 & 11.80 & 1013.07 & 13.53 & 1274.1 & 1.11 \\
\hline Cheorwon & 10.41 & 1377.01 & 68.82 & 11.00 & 997.84 & 12.62 & 1377.01 & 1.14 \\
\hline Daegwallyeong & 7.39 & 1239.21 & 72.71 & 9.40 & 925.99 & 10.70 & 1239.21 & 1.12 \\
\hline Chuncheon & 11.52 & 1345.22 & 70.17 & 11.82 & 1007.13 & 13.57 & 1345.22 & 1.13 \\
\hline Bukgangneung & 12.56 & 1214.39 & 61.81 & 10.97 & 1005.77 & 12.56 & 1214.39 & 1.10 \\
\hline Gangneung & 13.40 & 1235.08 & 57.94 & 10.85 & 1012.22 & 12.42 & 1235.08 & 1.11 \\
\hline Donghae & 13.20 & 1119.52 & 63.66 & 11.82 & 1010.44 & 13.55 & 1119.52 & 1.07 \\
\hline Wonju & 12.34 & 1281.38 & 63.7 & 11.25 & 998.32 & 12.89 & 1281.38 & 1.11 \\
\hline Yeongwol & 11.58 & 1175.56 & 67.96 & 11.28 & 987.68 & 12.92 & 1175.56 & 1.09 \\
\hline Inje & 10.52 & 1194.21 & 66.9 & 10.45 & 992.38 & 11.94 & 1194.21 & 1.10 \\
\hline Hongcheon & 11.30 & 1185.43 & 66.13 & 10.94 & 999.54 & 12.53 & 1185.43 & 1.09 \\
\hline Taebaek & 9.17 & 1200.92 & 66.20 & 9.51 & 932.52 & 10.84 & 1200.92 & 1.11 \\
\hline Chungju & 11.99 & 1137.41 & 65.35 & 11.25 & 1002.74 & 12.89 & 1137.41 & 1.08 \\
\hline Cheongju & 13.30 & 1198.43 & 62.05 & 11.56 & 1009.48 & 13.26 & 1198.43 & 1.09 \\
\hline Chupungryung & 11.81 & 1121.51 & 66.53 & 11.27 & 987.25 & 12.90 & 1121.51 & 1.07 \\
\hline Jecheon & 10.33 & 1307.44 & 68.38 & 10.59 & 984.97 & 12.11 & 1307.44 & 1.13 \\
\hline Boeun & 11.38 & 1261.62 & 69.92 & 11.44 & 995.72 & 13.10 & 1261.62 & 1.11 \\
\hline
\end{tabular}

${ }^{* 1}$ MIs were calculated using the DI normalized to that in Phoenix, Arizona, and the WI normalized to that in Seogwipo, Korea. 
Table 1. Continued.

\begin{tabular}{|c|c|c|c|c|c|c|c|c|}
\hline Location & $\begin{array}{c}\text { Temp } \\
\left({ }^{\circ} \mathrm{C}\right)\end{array}$ & $\begin{array}{l}\text { Average annual } \\
\text { Precipitation } \\
\text { (mm) }\end{array}$ & $\begin{array}{l}\text { RH } \\
(\%)\end{array}$ & $\begin{array}{l}\text { Vapor } \\
\text { pressure } \\
(\mathrm{hPa})\end{array}$ & $\begin{array}{c}\text { Spot } \\
\text { atmospheric } \\
\text { Pressure } \\
(\mathrm{hPa})\end{array}$ & DI & WI & MI \\
\hline Seosan & 12.10 & 1238.28 & 76.96 & 13.20 & 1013.45 & 15.18 & 1238.28 & 1.09 \\
\hline Cheonan & 12.33 & 1190.51 & 68.59 & 11.95 & 1012.03 & 13.73 & 1190.51 & 1.09 \\
\hline Boryeong & 12.80 & 1164.21 & 74.19 & 13.38 & 1014.53 & 15.41 & 1164.21 & 1.07 \\
\hline Buyeo & 12.57 & 1277.43 & 71.9 & 12.51 & 1015.20 & 14.37 & 1277.43 & 1.10 \\
\hline Geumsan & 11.87 & 1229.32 & 69.03 & 11.50 & 996.07 & 13.18 & 1229.32 & 1.10 \\
\hline Gunsan & 12.92 & 1190.21 & 78.59 & 14.13 & 1013.77 & 16.29 & 1190.21 & 1.07 \\
\hline Jeonju & 13.69 & 1217.58 & 67.67 & 12.73 & 1009.76 & 14.63 & 1217.58 & 1.09 \\
\hline Buan & 13.07 & 1153.73 & 71.88 & 12.88 & 1015.27 & 14.80 & 1153.73 & 1.07 \\
\hline Imsil & 11.51 & 1333.533 & 70.50 & 11.44 & 987.17 & 13.09 & 1333.53 & 1.13 \\
\hline Jeongeup & 13.60 & 1311.74 & 69.42 & 12.86 & 1010.85 & 14.78 & 1311.74 & 1.11 \\
\hline Namwon & 12.48 & 1262.48 & 68.78 & 11.91 & 1003.19 & 13.66 & 1262.48 & 1.10 \\
\hline Jangsu & 10.92 & 1493.52 & 73.07 & 11.41 & 968.36 & 13.06 & 1493.52 & 1.17 \\
\hline Gochang & 13.62 & 1306.30 & 71.23 & 13.28 & 1009.58 & 15.28 & 1306.30 & 1.11 \\
\hline Sunchang & 12.70 & 1415.10 & 70.14 & 12.20 & 1001.54 & 13.97 & 1415.10 & 1.15 \\
\hline Mokpo & 13.84 & 1147.02 & 80.28 & 14.97 & 1011.95 & 17.29 & 1147.02 & 1.05 \\
\hline Yeosu & 14.61 & 1457.68 & 63.78 & 12.97 & 1008.10 & 14.92 & 1457.68 & 1.15 \\
\hline Heuksando & 13.56 & 1140.10 & 79.41 & 14.38 & 1007.17 & 16.56 & 1140.10 & 1.05 \\
\hline Wando & 14.41 & 1542.03 & 71.94 & 14.12 & 1012.14 & 16.27 & 1542.03 & 1.17 \\
\hline Jindo & 11.74 & 1451.84 & 77.42 & 12.62 & 960.26 & 14.46 & 1451.84 & 1.15 \\
\hline Yeonggwang & 13.06 & 1261.48 & 73.63 & 13.30 & 1012.05 & 15.22 & 1261.48 & 1.09 \\
\hline Jangheung & 13.73 & 1435.11 & 72.97 & 13.60 & 1010.92 & 15.66 & 1435.11 & 1.14 \\
\hline Haenam & 13.60 & 1273.51 & 73.98 & 13.59 & 1014.75 & 15.62 & 1273.51 & 1.09 \\
\hline Goheung & 13.88 & 1499.84 & 71.24 & 13.43 & 1009.78 & 15.44 & 1499.84 & 1.16 \\
\hline Ulleungdo & 12.67 & 1561.83 & 69.83 & 11.99 & 988.69 & 13.73 & 1561.83 & 1.19 \\
\hline Uljin & 12.72 & 1029.34 & 67.70 & 12.11 & 1009.56 & 13.88 & 1029.34 & 1.05 \\
\hline Andong & 12.52 & 999.93 & 64.53 & 11.42 & 999.34 & 13.10 & 999.93 & 1.05 \\
\hline Sangju & 12.70 & 1064.82 & 62.66 & 11.36 & 1004.71 & 13.03 & 1064.82 & 1.06 \\
\hline Pohang & 14.70 & 1065.46 & 63.50 & 12.99 & 1015.51 & 14.93 & 1065.46 & 1.05 \\
\hline Bonghwa & 9.91 & 1047.97 & 69.50 & 10.46 & 977.62 & 11.95 & 1047.97 & 1.06 \\
\hline Yeongju & 11.73 & 1217.48 & 64.67 & 11.00 & 990.88 & 12.59 & 1217.48 & 1.10 \\
\hline Mungyeong & 11.99 & 1224.26 & 60.93 & 10.62 & 995.90 & 12.15 & 1224.26 & 1.11 \\
\hline Yeongdeok & 13.38 & 964.57 & 62.38 & 11.71 & 1010.69 & 13.42 & 964.57 & 1.04 \\
\hline Uiseong & 11.88 & 888.36 & 67.86 & 11.46 & 1006.45 & 13.14 & 888.36 & 1.02 \\
\hline Gumi & 13.42 & 1022.47 & 64.74 & 12.14 & 1010.46 & 13.94 & 1022.47 & 1.04 \\
\hline Yeongcheon & 12.96 & 1025.90 & 63.61 & 11.44 & 1004.80 & 13.10 & 1025.90 & 1.05 \\
\hline
\end{tabular}


Table 1. Continued.

\begin{tabular}{|c|c|c|c|c|c|c|c|c|}
\hline Location & $\begin{array}{c}\text { Temp } \\
\left({ }^{\circ} \mathrm{C}\right)\end{array}$ & $\begin{array}{l}\text { Average annual } \\
\text { Precipitation } \\
\text { (mm) }\end{array}$ & $\begin{array}{l}\text { RH } \\
(\%)\end{array}$ & $\begin{array}{c}\text { Vapor } \\
\text { pressure } \\
(\mathrm{hPa})\end{array}$ & $\begin{array}{c}\text { Spot } \\
\text { atmospheric } \\
\text { Pressure } \\
(\mathrm{hPa})\end{array}$ & DI & WI & MI \\
\hline Changwon & 14.69 & 1469.44 & 59.8 & 12.94 & 1011.39 & 14.89 & 1469.44 & 1.15 \\
\hline Tongyeong & 14.51 & 1516.49 & 70.52 & 13.93 & 1012.07 & 16.03 & 1516.49 & 1.16 \\
\hline Jinju & 13.32 & 1552.87 & 66.46 & 12.20 & 1012.57 & 14.00 & 1552.87 & 1.19 \\
\hline Kimhae & 15.13 & 1316.2 & 60.98 & 12.89 & 1009.43 & 14.76 & 1316.2 & 1.11 \\
\hline Bukchangwon & 14.34 & 1399.16 & 63.88 & 12.70 & 1010.06 & 14.43 & 1399.16 & 1.14 \\
\hline Yangsan & 14.81 & 1420.33 & 61.00 & 12.50 & 1015.15 & 14.31 & 1420.33 & 1.14 \\
\hline Geochang & 12.01 & 1195.1 & 68.62 & 11.72 & 989.11 & 13.45 & 1195.1 & 1.09 \\
\hline Hapcheon & 13.33 & 1325.69 & 65.06 & 11.84 & 1012.26 & 13.58 & 1325.69 & 1.12 \\
\hline Miryang & 14.02 & 1178.78 & 63.63 & 12.24 & 1014.61 & 14.06 & 1178.78 & 1.08 \\
\hline Sancheong & 13.22 & 1530.7 & 63.87 & 11.81 & 999.60 & 13.54 & 1530.7 & 1.18 \\
\hline Geoje & 14.72 & 1849.5 & 64.9 & 13.08 & 1010.44 & 15.04 & 1849.5 & 1.28 \\
\hline Namhae & 14.54 & 1913.9 & 65.43 & 13.10 & 1010.70 & 15.06 & 1913.9 & 1.30 \\
\hline jeju & 16.23 & 1439.68 & 69.08 & 14.63 & 1013.93 & 16.84 & 1439.68 & 1.13 \\
\hline Gosan & 15.69 & 1171.52 & 74.29 & 15.24 & 1007.33 & 17.57 & 1171.52 & 1.05 \\
\hline Seongsan & 15.64 & 2053.90 & 73.74 & 15.13 & 1013.77 & 17.45 & 2053.90 & 1.34 \\
\hline Seogwipo & 16.96 & 2091.94 & 70.83 & 15.61 & 1009.66 & 18.03 & 2091.94 & 1.34 \\
\hline
\end{tabular}

Table 2. Moisture indexes of 20 cities in Canada and the United States.

\begin{tabular}{lccccccc}
\hline \multicolumn{1}{c}{ City } & WI & DI & MI & \multicolumn{1}{c}{ City } & WI & DI & MI \\
\hline \hline New Orleans LA & 1601.4 & 36.44 & 1.07 & Pittsburgh PA & 931.1 & 30.19 & 0.97 \\
St Johns NF & 1193.8 & 10.20 & 1.11 & Madison WI & 803.9 & 24.67 & 0.96 \\
Shearwater NS & 1178.1 & 13.11 & 1.17 & Ottawa ON & 701.8 & 22.96 & 0.91 \\
Vancouver BC & 1058.2 & 16.10 & 1.04 & Toronto ON & 625.6 & 21.58 & 0.91 \\
Atlanta GA & 1306.0 & 39.02 & 0.95 & San Francisco CA & 506.6 & 25.58 & 0.87 \\
Orlanda FL & 1274.1 & 41.69 & 0.92 & Calgary AB & 293.4 & 26.71 & 0.84 \\
Houston TX & 1211.4 & 41.14 & 0.91 & Fort Worth TX & 857.3 & 53.57 & 0.72 \\
Victoria BC & 813.0 & 17.03 & 1.02 & Colorado Springs CO & 424.5 & 45.33 & 0.70 \\
Seattle WA & 927.4 & 24.38 & 0.95 & Phoenix AZ & 205.1 & 129.47 & 0.05 \\
Chicago IL & 914.3 & 29.01 & 0.97 & Las Vegas NV & 108.2 & 117.78 & 0.09 \\
\hline
\end{tabular}

MI is based on hourly values. WI was normalized to that in Seogwipo, and DI was normalized to that in Phoenix AZ. 


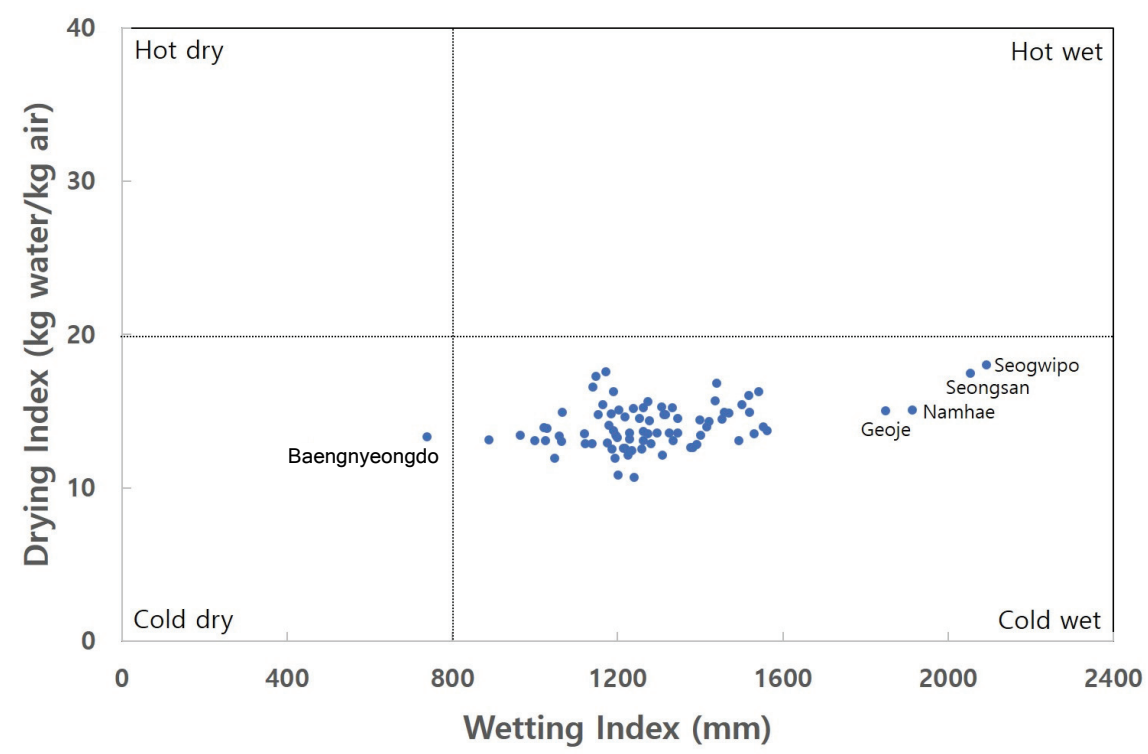

Fig. 1. Scatter plot showing the mean drying index and wetting index for 82 locations.

may be explained by the application of equal weighting for the DI and WI when combining them into a MI. Neglecting wet or dry spells may also be a reason.

A mathematical evaluation of the relation between climate and wood moisture content, particularly on wood surfaces, may facilitate better understanding of premature failures that frequently occur in wooden houses or structures from a maintenance point of view. The MI approach offers a way to group and compare countries into zones related to potential moisture problems. In addition, it has the potential to quantitatively assess the mechanisms of the effect of climate on wood moisture content. Further research to investigate the relation between the MI and the wood moisture content is required to provide a more integrated interpretation for practical purposes.

\section{CONCLUSION}

The following conclusions can be drawn from this study.
1. MI was determined using hourly weather data for 82 locations recorded from 2009 to 2017.

2. Seogwipo had the highest MI of 1.34 , followed by Seongsan, Namhae, and Geoje. Baengnyeongdo had the lowest MI of 0.99 .

3. Almost all the locations in Korea can be classified as regions of severe moisture loading.

4. Further research is required to investigate the relation between MI and moisture content on wood surfaces and to gain insights into practical applications.

\section{ACKNOWLEDGMENT}

This study was supported by the Gyeongnam National University of Science and Technology Grant in 2017.

\section{REFERENCES}

Bailey, H.P. 1958. A simple moisture index based upon 
a primary law of evaporation. Geografiska Annaler 40: $196-215$.

Boyd, D.W. 1963. Driving rain map of Canada, Technical Note 398, Division of Building Research, National Research Council of Canada, Ottawa.

Chouinard, K.L., Lawton, M.D. 2001. Rotting wood framed apartments-not just a Vancouver problem. Proceedings of the Eighth Conference on Building Science and Technology, Toronto, Canada. pp. 304-318.

Cornick, S.M., Dalgliesh, W.A. 2003. A moisture index to characterize climates for building envelope design. Journal of Building Physics 27(2): 1-39.

Cornick, S.M., Dalgliesh, W.A., Said, N.M., Djebbar, R., Tariku, F., Kumaran, M.K. 2002. Report from task 4 of MEWS-environmental conditions final report, Institute for Research in Construction, National Research Council of Canada, IRC-RR1130.

Kim, T., Ra, J.B., Kang, S.M., Wang, J. 2011. Determination of decay hazard index (Scheffer index) in Korea for exterior above-ground wood.
Journal of the Korean Wood Science and Technology 39(6): 531-537.

Kim, T., Ra, J.B. 2013. Decay hazard (Scheffer) index values in Korea for exterior aboveground wood. Forest Products Journal 63(3-4): 91-94.

Kim, T., Ra, J.B. 2014. Change of decay hazard index (Scheffer index) for exterior above-ground wood in Korea. Journal of the Korean Wood Science and Technology 42(6): 732-739.

Lstiburek, J.W. 2001. Hygrothermal climate regions, interior climate classes, and durability. Proceedings of the Eighth Conference on Building Science and Technology, Toronto, Canada, pp. 319-329.

Ra, J.B. 2017. Determination of driving rain index in Korea. Journal of the Korean Wood Science and Technology 45(1): 36-42.

Russo, J.A. 1971. The complete money-saving guide to weather for contractors. Environmental Information Services Associates, Connecticut, USA, pp. 78-79. Setliff, E.C. 1986. Wood decay hazard in Canada based on Scheffer's climate index formula. The Forestry Chronicle, October: 456-459. 